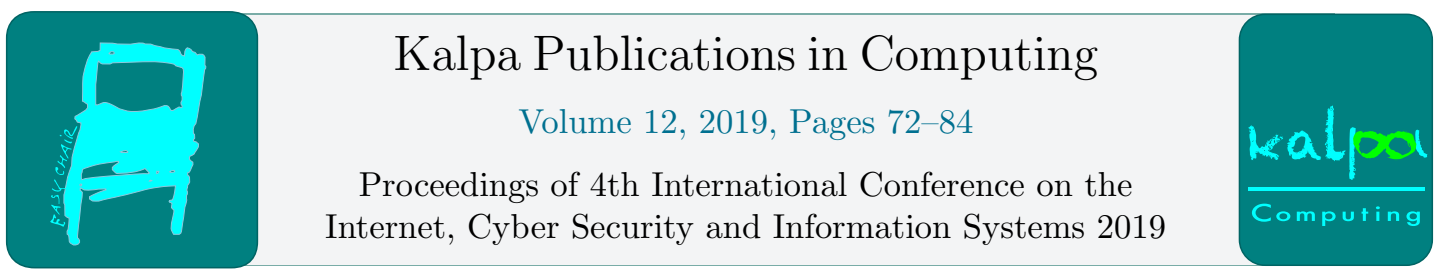

\title{
Blockchain Technology and Smart Universities
}

\author{
Thabo J. Gopane
}

University of Johannesburg, Johannesburg, South Africa

tjgopane@uj.ac.za

\begin{abstract}
The objective of this paper is to conduct a conceptual assessment of blockchain technology applications to universities. The paper will first address two related questions namely, the concept of smart university, and the architecture of blockchain technology. This paper contributes towards the topical debate of whether the claimed blockchain technological transformation is a hype, reality, revolution, or just an ordinary computing upgrade. It follows that if blockchain is a significant technological advancement then it can only be ignored at own's peril. This research should benefit innovation policy decisions in the academia for out-of-the box thinking regarding internal control systems and product offering for smart universities.
\end{abstract}

\section{Introduction}

The Universities and academia around the world are faced with persistent operational challenges (Broggi et al., 2018) including unsatisfactory lecturer-employment contracts, inadequate lecturerstudent learning relationship, high administrator-to-academic ratios, and insufficiency of solution offered by MOOCs (massive open online courses), among others. Whatever is the true depiction of university operational restrictions, most will concur that innovative solutions are needed. Indeed cost constraints impair education technological progress, inter alia. One way to conceptualize the overall high education advancement is the notion of smart university. The adjective, smart does not necessarily mean that its ordinary English antonym is implied as alternative. While there does not appear to be an agreed upon definition of the concept, smart university, intuitively a range of definitions seems to harmonise around similar ideas of modernisation such as the description articulated by Uskov et al. (2018:2) that:

The concept of a 'Smart University' is an emerging and fast evolving area that represents the creative integration of innovative concepts, smart software and hardware systems, Smart Classrooms with state-of-the-art technologies and technical platforms, Smart Pedagogy based on modern teaching and learning strategies, Smart Learning Analytics and academic analytics....

According to Tikhomirov \& Dneprovskaya (2015), "Smart University is a concept that involves a comprehensive modernization of all educational processes. ...". This intuition is broadly captured in Figure 1 and elaborated in Table 1 to show the status quo of the traditional high education system in 
relation to Smart University improvements. In this context, high education innovations are conceived as a combination and interaction of Self-directed, Motivated, Adaptive, Resource enriched, and Technology embedded (smart) university environment. The enthusiasts (Hwang, 2014, Tikhomirov \& Dneprovskaya, 2015, Uskov et al., 2019) of smart university belief that there is a fundamental change from traditional to a modern concept of university smartness.

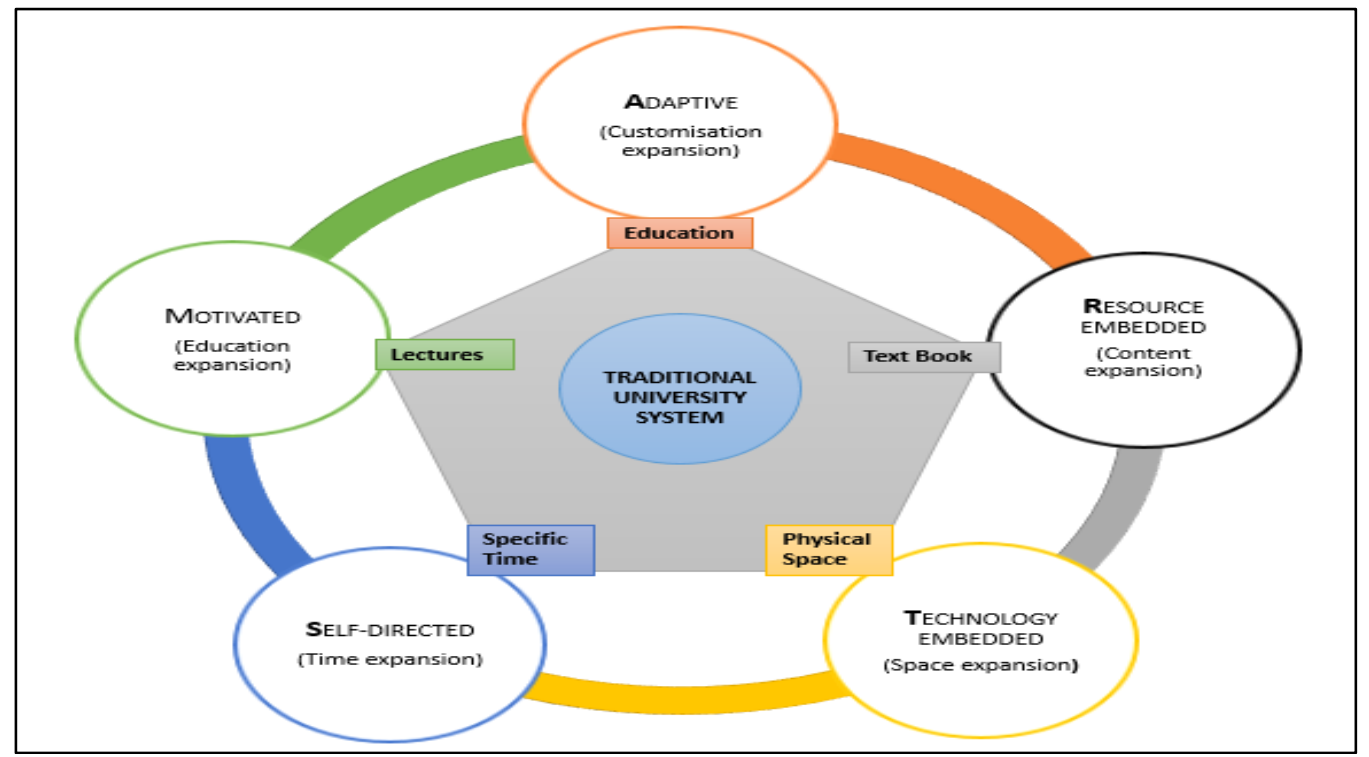

Figure 1: Smart University Taxonomy. Source: Adapted from Adapted from Heinemann and Uskov (2018).

The five pillars (shown in Figure 1) of smartness address university improvement as explained in Table 1. In view of the above, one can argue that all universities are smart, and continue to smarten at different paths of advancement. For instance, a Self-directed feature of smart university says that a traditional university system often follows a rigid day-time time tables, and a smart university stand to benefit from flexible time expansion via just-in-time, or any-time online opportunities.

\begin{tabular}{|l|l|l|}
\hline \multicolumn{3}{|l|}{$\begin{array}{l}\text { Table 1: Schematic contrast of smart university from a traditional high education system } \\
\text { Source: Adapted from Heinemann and Uskov (2018). }\end{array}$} \\
\hline Smartness feature & $\begin{array}{c}\text { Traditional } \\
\text { University System }\end{array}$ & \multicolumn{1}{c|}{ Innovation } \\
\hline Self-directed: & Specific Time Table & Time expansion: just in time, any time \\
\hline Motivated: & $\begin{array}{l}\text { Lectures, or physical } \\
\text { classes }\end{array}$ & $\begin{array}{l}\text { Teaching methods expansion: by } \\
\text { collaborating learning, experiential learning, } \\
\text { communication }\end{array}$ \\
\hline Adaptive: & Education Content & $\begin{array}{l}\text { Customisation expansion: by improved } \\
\text { customization, needs focused. }\end{array}$ \\
\hline Resource enriched: & Traditional Textbooks & $\begin{array}{l}\text { Content expansion: increased online study } \\
\text { materials, creativity skills }\end{array}$ \\
\hline $\begin{array}{l}\text { Technology } \\
\text { embedded }\end{array}$ & Physical space & $\begin{array}{l}\text { Space expansion: home, mobile, global, } \\
\text { local }\end{array}$ \\
\hline
\end{tabular}


The question that arises is how does smart universities and blockchain technology relate? An obvious and simple link is the Technology embedded expansion stand to benefit from blockchain technology beneficiation. One observation that emerges from the literature is that there seem to be separate research dimensions. On one hand, a broad research effort focusing on high education smartness (smart pedagogy, smart e-learning, smart campus, smart universities, and such like). On the other hand, there is research trend that focuses on the implication or application of the $4^{\text {th }}$ industrial revolution technologies towards different use-cases including institutions of learning. While the two research dimensions are by their computer nature related, the research questions do not seem to overlap much. The view of this paper is that this research gap or undesirable research pattern should not be allowed to continue. This paper should be seen as a step towards contributing to the research that will close the gap. This paper does this by discussing both smart universities and blockchain in one paper. The rest of this paper is organized as follows: Section 2 explains blockchain technology in terms of its definition, architecture, and operational design. Section 3 explores the question of whether blockchain technology is a hype or reality. Section 4 outlines blockchain technology application to universities, and a sample of existing use cases. Section 5 concludes.

\section{Blockchain: Concept, Architecture and Operational Design}

In 2008 the architecture of blockchain application in cryptocurrency was conceptualised by a person or a group of people using the pseudonym, Satoshi Nakamoto in a manuscript published online titled, 'Bitcoin: A Peer-to-Peer Electronic Cash System' (Nakamoto, 2008). A year later, the operational rules drafted in this paper were later used to implement the transaction system for Bitcoin virtual currency. The core idea of blockchain is based on a database known as a distributed ledger, whose data contents must first be agreed upon by network users for inclusion or alteration. Once the information item (or its modified version) has satisfied a consensus standard, then the information is batched into a block which in turn is appended to the preceding sequence of blocks. The concept of blockchain makes the participation of the trusted third party irrelevant, without losing transaction trust itself. Cryptographic encoding of data in the blocks ensures that data is safe from inadvertent and malicious tampering thus establishing confidence among network users.

The concept of blockchain emerged out of a novel integration of existing technology like, public key encryption (Diffie \& Hellman, 1976); digital time stamping (Haber \& Stornetta, 1991); and the Hashcash proof of work (Back, 2002), among others. In order to introduce a cryptocurrency oriented blockchain system, Nakamoto (2008) added consensus protocol to existing innovation to support the incentivised proof-of-work by network participants. This simply means that network participants are paid to validate transaction data by solving a mathematical puzzle.

Distributed Network: The blockchain system operates in peer-to-peer (P2P) network where participants are linked via nodes or computers. Each computer has the same access authority to function concurrently as both server and client. The blockchain system is in effect a record book or a computer ledger. The ledger records are continuously and simultaneously updated by the network participants, which anyone may join autonomously and exist at free will.

Operational design: Operationally, the blockchain technology is a system for executing transactions and data storage. The functions are executed at three levels, as demonstrated in Figure 3 namely: blockchain software, consensus protocol, user-interface application (e.g. wallet), where the physical interaction is activated via laptops, tablet, desktop, and mobile phones. 
Therefore, the novelty of blockchain technology is powered by the three complementary elements: distributed ledger that yields transparency and synchronization; the consensus protocol which negates the need for trust; and user-interface application with characteristics of immutability and traceability (Pisa and Juden, 2017). Further technical details of blockchain technology include encryption keys, cryptographic hash, merkle tree, block chaining, and consensus protocol, which are explained next

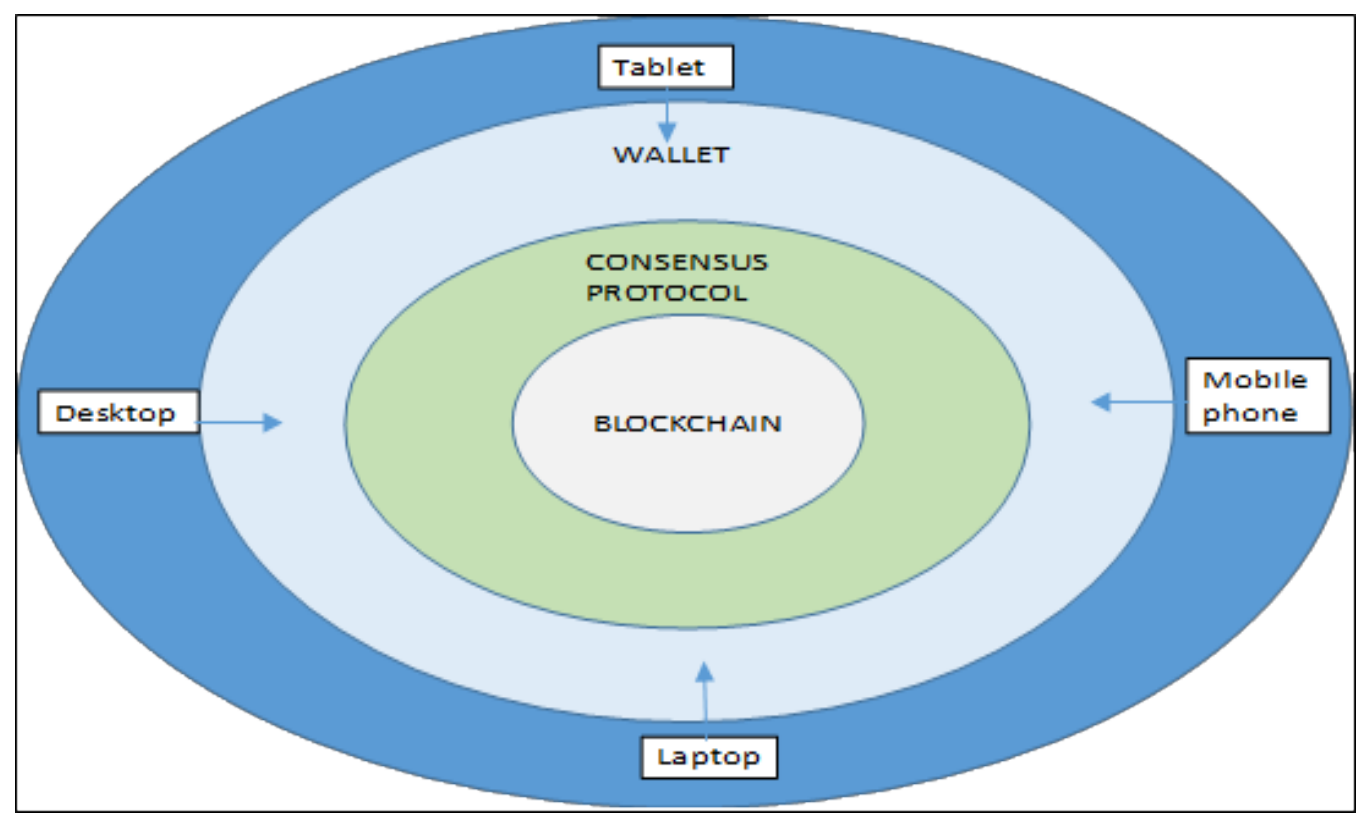

Figure 2: An intuition of the blockchain architecture

Digital Identity through encryption: A public key is a string of characters (a form of identity) associated with a particular participant but it is made publically known to other users. A private key is a string of characters (second identity) for a participant but unlike the public key, a private key must be made absolutely private and secured like a bank account's personal identification number (pin). Therefore both keys provide secure digital identity for a blockchain network participant.

Cryptographic Hash: Blockchain uses a type of encryption called cryptographic hash. A hash is an alphanumeric string which is a computer output produced from given input. The measure of the hash depends on the programmer's decision, but the hash function will produce equal-sized outputs, regardless of the input size. For example, Bitcoin's Secure Hash Algorithm 256-bit (SHA-256) produce 64-character hash, irrespective of the magnitude of input. The same input will yield the same hash, all the times. A change to input (no matter how minute) will always generate a significantly different output. It is impossible to 'reverse engineer' an output to determine the corresponding input.

Merkle Tree: This is a log of many messages or captured information pieces combined into a block, as demonstrated in Figure 4. Through the process of linking the leaves of the tree into Merkle Root, this achieves an important function of having one digital key signing many messages (or data sets). Since all transaction data points are linked together in the Merkle Root, the Root will be sensitive to any tampering within the block. The merkle tree is named after the inventor of cryptographic hashing, and co-inventor of public key encryption, Ralph Charles Merkle (see Merkle, 1979). The information 
is batched together into a merkle tree within the block. The block header is composed of a block number (in sequence); pointer (previous header hash); Merkle Root; and a time stamp (in chronological order). One block at a time over time, and blocks linked together by pointers, where each pointer encompasses block header hash of the preceding block. The block identifying details are broadcast out to the network users for validation.

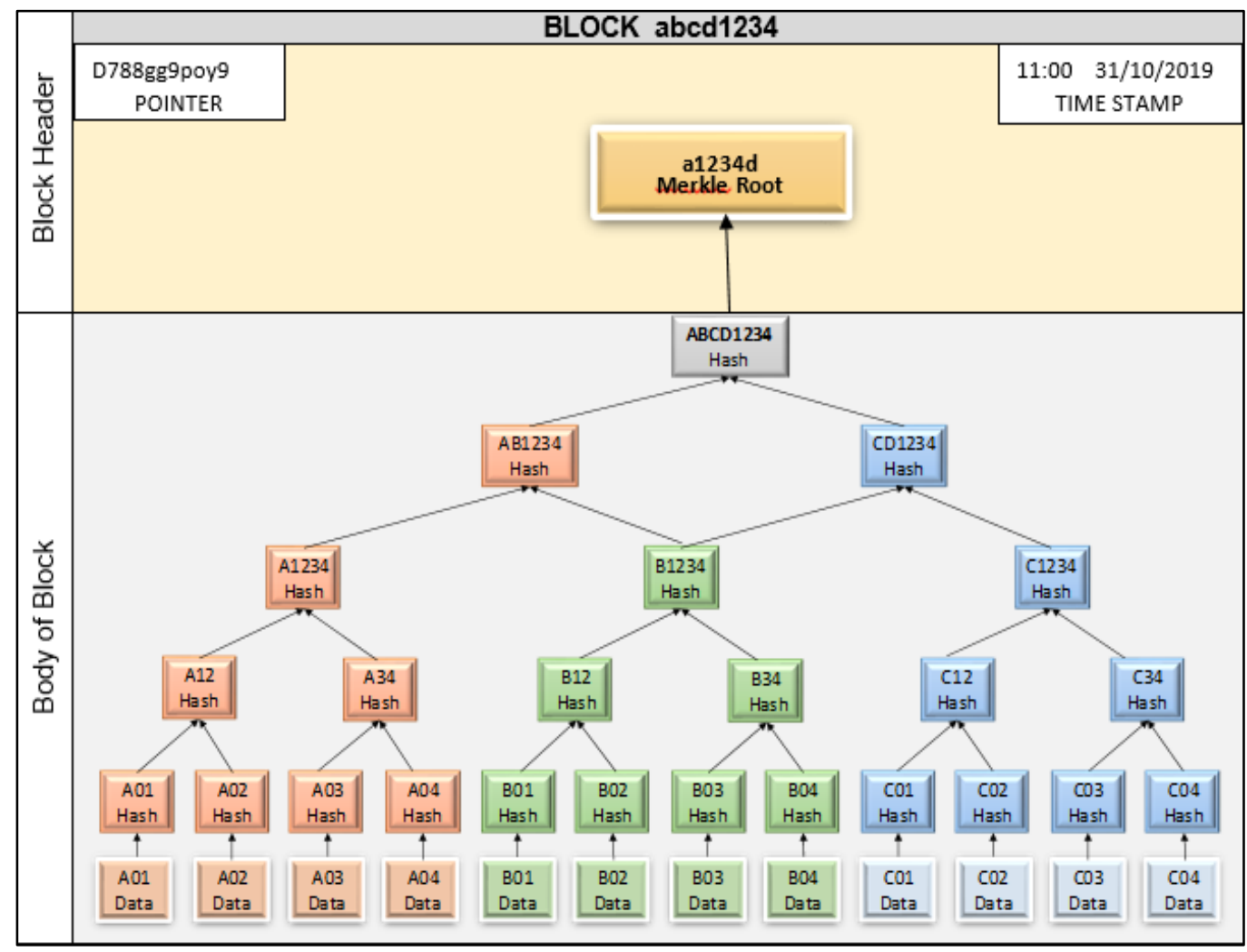

Figure 3: A demonstration of merkle tree with twelve leaves

Protocol Consensus: In order for a block to be added to the exiting sequence of blocks, it must satisfy the protocol consensus. The consensus method will depend on the design of network, and the choice of participants. Possible consensus methods may involve, solving a mathematical problem as in Bitcoin, or voting, or satisfying some pre-set consistent criterion. In a cryptocurrency network, like Bitcoin and other altcoins, the participants are incentivised to carry out this transparent record updating and validation process called, proof of work. For example, in Bitcoin network this verification process is primarily intended to stop the possibility of double-spending problem. No one must be able to take ownership of the bitcoins he/she does not own.

Security issues: Any change or tampering with the underlying pieces of information in a particular block, will spread over the entire merkle tree and distort the Merkle Root. Consequently, the block header hash will be affected which in turn will alter the pointer in the subsequent block. From this point, the chaining validity will break down. In order to update and correct such malfunction, it will require updating the entire merkle tree, and the associated databases in the network of participants. Since the interests of participants are linked within the blockchain system, this minimises system attack 
from within. Further, the huge amount of computing required to undo the merkle tree serves as security deterrence.

Network Access: Blockchain network may be designed according to the desired or predetermined access structure, as demonstrated in Figure 5. Possible authorisation types include permissionless or, permissioned network, or even some combination of both. In a permissionless network users are able to view ledger information, submit information transactions, host ledger copy, and participate in the information validation process. Due to the potential number of pseudonymous participants, a possibility exist of a member with malicious intent, but may not possess the required computing capacity or the necessary incentive to carry out his malicious intentions.

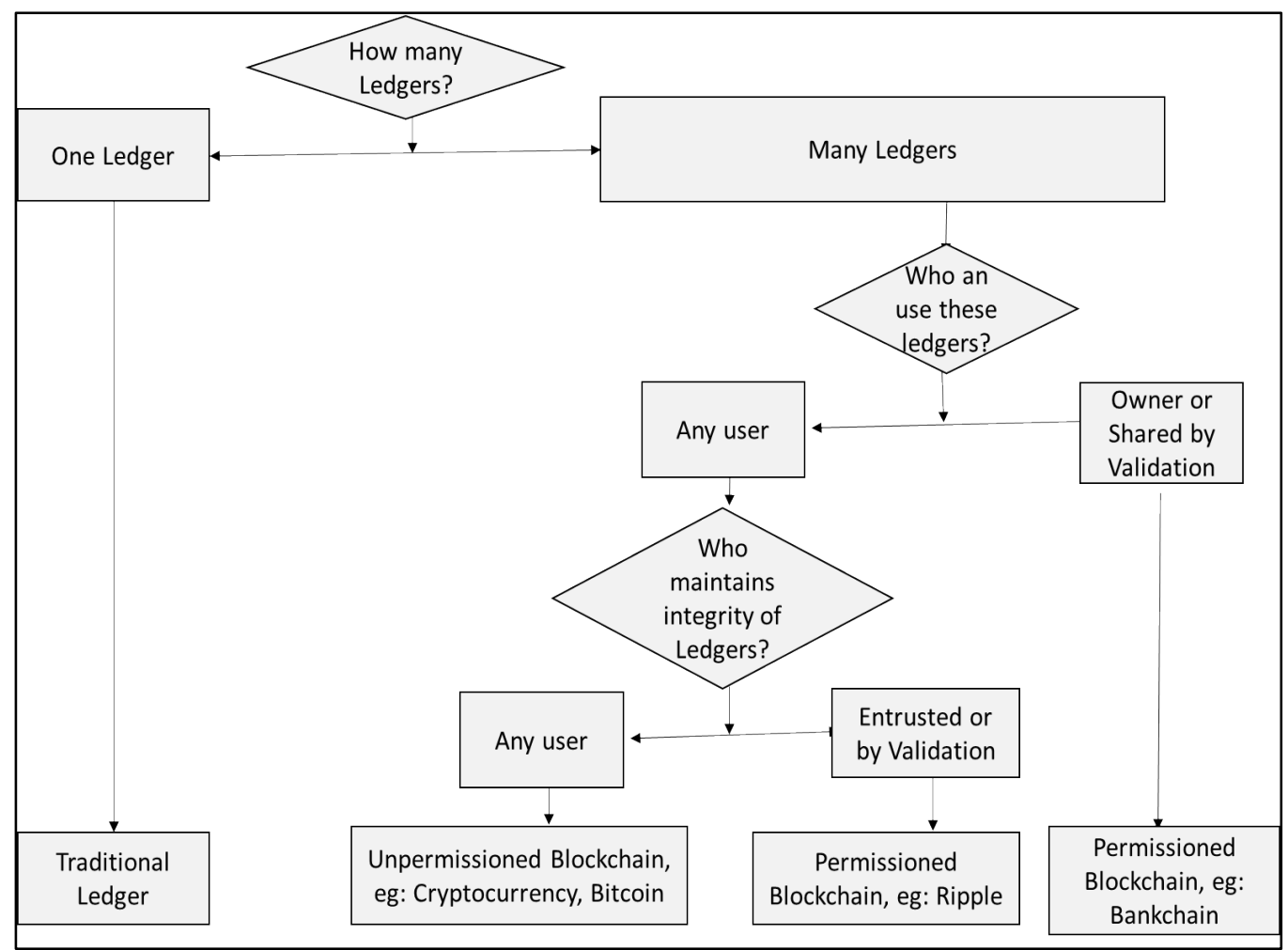

Figure 4: A demonstration of blockchain access types and the associated networks classification.

Adapted from: Government of United Kindom (2016)

On the other hand, in a permissioned network potential members must receive authorisation or permission to be authenticated as network participants. Such permission may be in the form of pre-set criteria, or vetting, according to the users preferences. The network participation is likely to have a smaller size, and to be for a particular purpose, which may be dealing with sensitive information. The fifty one per cent attack is a network domination of a group or individual who has a fifty one per cent or more of hashing power. This domination can influence the participation, process, output, and validity of the merkle tree and the eventual blockchain integrity. Nevertheless, this possibility is deemed remote due to the prohibitive computing cost involved.

The blockchain technology has been in operation since 2009 through cryptocurrency. Nevertheless, the status quo is that blockchain is still in the infant stage for wide application. Notwithstanding, there 
are active and emerging initiatives for blockchain projects such as IBM, Linux. Cisco and Intel are collaborating to create blockchain platform for wide business application. Since 2014 the Ethereum platform is involved into providing capability for users to programme self-executing computer scripts, (called smart contracts), and empowering technologists with a blockchain builders kit.

\section{Blockchain Techology: hype or not?}

At its core, blockchain technology brings along an important value of business trust, which concurrently disrupts the accepted practice and necessity of trusted third parties or intermediaries in contractual relations. The concept of trust in business transactions is well-known and critical (as surveyed by Algan \& Cahuc, 2013) and long acknowledged by economists (Arrow, 1972:24) that, "Almost every commercial transaction has within itself an element of trust....". This gives rise to the question: to what extent does blockchain has capacity to disrupt business activities (like contracting, data sharing, citizen-identity recording, asset keeping, intellectual property registration, learning, and other notary attestation)? Some authors, like Iansiti and Lakhani (2017) have pondered the "truth about blockchain" technology in terms of hype vs long run dependability (Pisa \& Juden, 2017).

Contracts, transactions, and the records of them are among the defining structures in our economic, legal, and political systems. They protect assets and set organizational boundaries. They establish and verify identities and chronicle events. ... and yet these critical tools and the bureaucracies formed to manage them have not kept up with the economy's digital transformation. Blockchain promises to solve this problem. Iansiti and Lakhani (2017:3, emphasis added).

Is blockchain a hype that is driven by non-market fundamentals? It turns out that this is a very old question. A mania-fueled market speculation is conceivable across industries. Cooper et al. (2001) reviews the related literature over a long period including the Dutch tulip bulb craze (in 1630's); South Sea Bubble (in 1710's); railroad stock (in US, 1850's) and mining stocks (in US, 1960's). Cooper et al. (2001) observed that these were all fresh glamour industries at the time with growth possibilities but volatile. Another anecdotal evidence in support of the hype hypothesis come from stock market responses to company name changes. While pure name change should have no effect to stock market (Bosch \& Hirschey, 1989, and Karpoff \& Rankine, 1994), some studies found positive stock price reaction (Cooper et al., 2001) for companies that altered their names to add dotcom, net, or internet. Regarding blockchain, three US exchange listed companies made a pure name change to include blockchain in their names. Bioptix changed its name to Riot Blockchain (price increased by more than $400 \%$ ). Long Island Ice Tea changed its name to Long Blockchain (price increased by more than $180 \%$ ). Computer Literacy, Inc. changed its name to Fatbrain.com (price increased by 33\%). In all these cases the stock price reaction was simply hype driven speculative activity.

Nevertheless, positive stock market reaction is possible if the name change signals a new relevant business model (Horsky \& Swyngedouw, 1987, and Lee, 2001), or introduces a valid name association (Peng \& Xiong, 2006). The case against blockchain hype hypothesis may be assisted to a degree through the Deloitte Global Blockchain Survey (2019). The Deloitte analysts surveyed 1386 Chief Executive Officers (CEO's) around the world (a sample of 12 countries): Brazil, Canada, China, Germany, Hong Kong, Israel, Luxembourg, Singapore, Switzerland, United Arab Emirates, United Kingdom of Great Britain, and United States of America. Figure 5 shows that $12 \%$ of CEO's plan to expense less than half a million towards blockchain projects, compared to $18 \%$ who plan to invest the highest amount of more than $\$ 10 \mathrm{~m}$ (US Dollars). The graph peaks at $27 \%$ indicating that the majority 
of the CEO's plan to allocate between one and five millions of US Dollars before the end of 2020 . According to Agency Theory in Corporate Finance (Jensen \& Meckling, 1976), in most cases CEO's are subject to the monitoring by many business stakeholders like Board of Directors, financial markets, employees, and regulators. So, it is conceivable that one may expect a CEO to be more prudent and not be easily hyped by new technologies. Therefore, for this reason and a consideration that the foundations of blockchain existed before the speculative cryptocurrencies, it will be hard to sustain an argument that that emerging applications of blockchain technology are a hype.

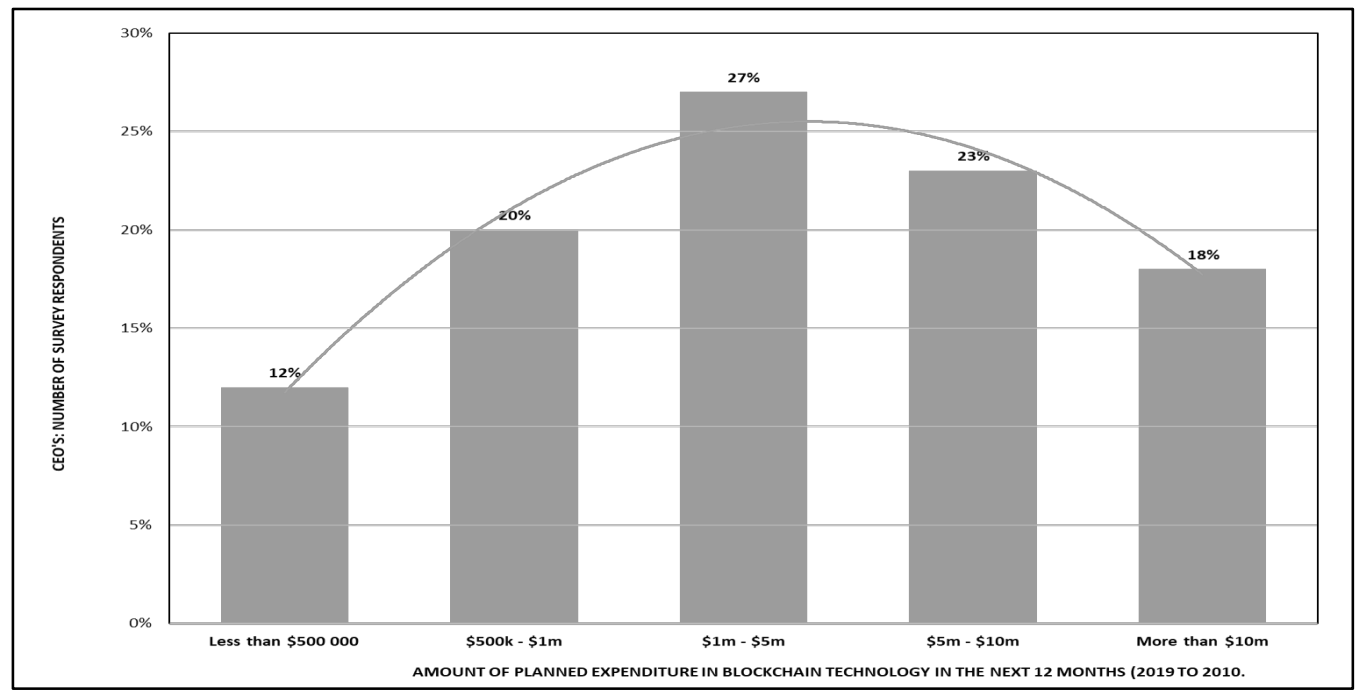

Figure 5: Planned Expenditure in Blockchain Technology by industry CEO's around the world. Source: Aggregated from Deloitte Global Blockchain Survey (2019).

Further, blockchain technology appear to have global support by highly influential international organisations such as the Bank of England (2016), World Economic Forum (2016, 2017); the European Central Bank (2017), the G20 organisation (Maupin, 2017), as well as World Bank Group (2017), among others. Market observations indicate that the private sector is aware of blockchain's promises. Gartner Incorporated is a global and large multi-million dollar consulting firm listed on the NYSE and headquartered in USA, with regional offices in Australia, Brazil, Japan, and United Kingdom. The Gartner's research analysts, Kandaswamy et al. (2017) predict that blockchain will have a potential to add $\$ 176$ billion in business value by 2025 , and $\$ 3.1$ trillion by 2030 . Beyond this, Gartner Incorporated has published ample other research reports to inform their business clients about blockchain including, Practical Blockchain: A Gartner Trend Insight Report; The Evolving Landscape of Blockchain Technology Platforms; Forecast: Blockchain Business Value, Worldwide, 2017-2030; What CIOs Should Tell the Board of Directors About Blockchain; Blockchain: Managing Business Expectations; The Disruptive Potential of Blockchain Technology. If the above submission make the blockchain hype hypothesis untenable, then an inquiry about blockchain's capacity to contribute to university smartness is relevant and ought to be addressed.

\section{Blockchain Technology Possibilities for Universities}

Figure 6 shows that universities as economic citizens are equally vulnerable to the risk of data safety, and inadequate internal control systems that are supposed to help. The graph reports that in the period, 2008-2016, eleven U.S universities has suffered a loss of 5816000 data records. This is approximately 
66000 loss of data records per year per university. Given other known cost inefficiencies and operational constraints, this in part, has led a group of Oxford University academics (Broggi, 2018) to posit that blockchain has possible solution to these challenges (or in part), if not, ameliorate them significantly.

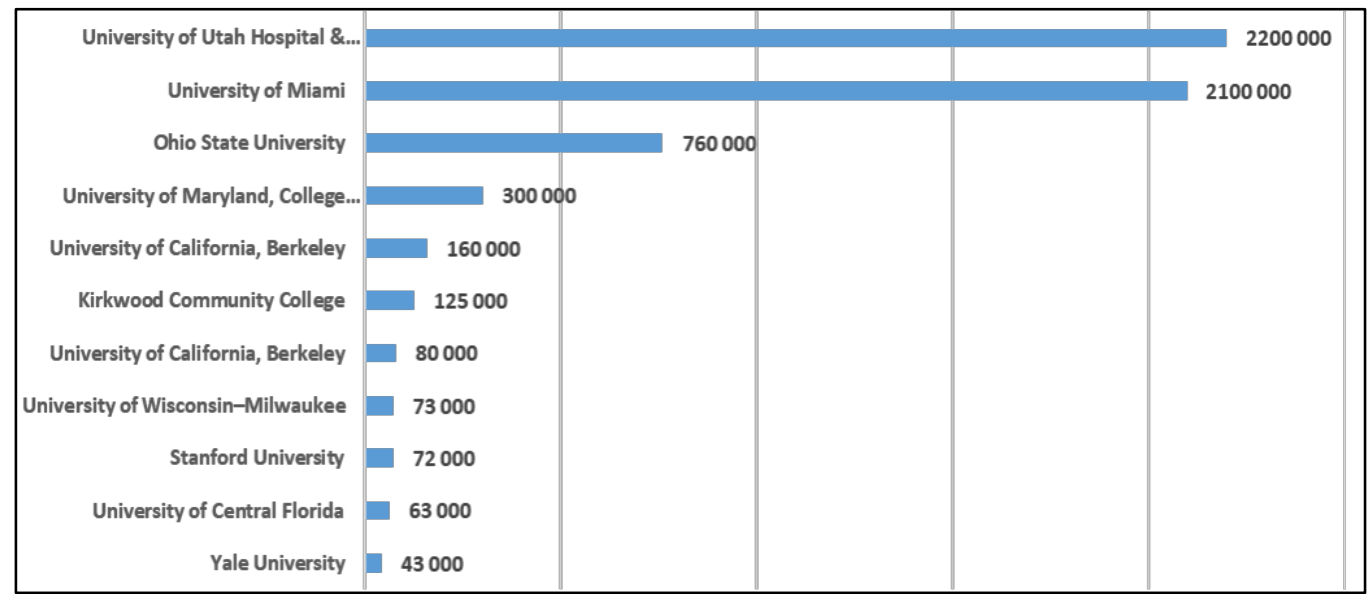

Figure 6: Loss of data records per selected universities in the USA. Source: Data Breaches (n.d)

The revolution and evolution of blockchain technology appear to be driven by its possible capacity to handle problems that involve double-spend, consensus, immutability, transaction trust, identity, general data security. Such blockchain applications will vary according to design-characteristics including, the content of what is stored on the ledger, the process used to reach consensus, and the degree to which the ledger is permissioned (Pisa \& Juden, 2017). Therefore, relevant feasibility studies are called upon for thoughtful blockchain application possibilities by industries and academia.

Block Application Opportunities for Universities: In the discussion that follows, Table 2 refers. The benefits of blockchain implementation for universities are plausible at different levels including, universal applications, and academic-specific usage. The payoff of blockchain application by universities is likely to be realised steadily over time with varying positive spillover benefits as outlined in Table 2, which draws from Nakamoto (2008), Swan (2015), Pisa and Juden (2017), and Broggi (2018).

\begin{tabular}{|l|l|l|}
\hline \multicolumn{3}{|c|}{ Table 2: Blockchain Applications for Universities. } \\
\hline No & \multicolumn{1}{|c|}{ Application } & \multicolumn{1}{c|}{ Benefit } \\
\hline 1 & Blockchain Possibilities for Universities I: Universal Usage \\
\hline 2 & Disintermediation & $\begin{array}{l}\text { To store and activate transaction contract when they } \\
\text { are due, automatically. }\end{array}$ \\
\hline 3 & Serve as Registry & $\begin{array}{l}\text { Removes the need of the trusted middle party, with its } \\
\text { associated cost, risk, and time inefficiencies. }\end{array}$ \\
\hline 4 & $\begin{array}{l}\text { Process Integrity and } \\
\text { Immutability }\end{array}$ & $\begin{array}{l}\text { Provides time-stamped systematic record of assets. } \\
\text { dishonesty, tampering }\end{array}$ \\
\hline 5 & $\begin{array}{l}\text { Preservation of Intellectual } \\
\text { Property }\end{array}$ & $\begin{array}{l}\text { Removes the need of intermediaries for the } \\
\text { management and preservation of personal works of } \\
\text { art, and innovation. }\end{array}$ \\
\hline
\end{tabular}




\begin{tabular}{|c|c|c|}
\hline 6 & $\begin{array}{l}\text { Advantages of Data Security } \\
\text { through Decentralisation }\end{array}$ & $\begin{array}{l}\text { Decentralised data ledgers removes the risk of one- } \\
\text { stop data failure (malicious, or system malfunction) }\end{array}$ \\
\hline 7 & Digital Identity & $\begin{array}{l}\text { To digitise personal identity details: passports, } \\
\text { national identity document, online account login, birth } \\
\text { certificate, proof of residence }\end{array}$ \\
\hline 8 & Decentralised Notary & $\begin{array}{l}\text { To capture the time-stamped attestation of document. } \\
\text { Document not stored but its existence is stored in hash } \\
\text { format. }\end{array}$ \\
\hline \multicolumn{3}{|c|}{ Blockchain Possibilities for Universities II: Academic Specific Usage } \\
\hline 9 & Digital Academic Certificate & $\begin{array}{l}\text { Provides instant and self-verification of academic } \\
\text { qualification, even when the university does not exist } \\
\text { anymore. }\end{array}$ \\
\hline 10 & $\begin{array}{l}\text { Massive Open Online Courses } \\
\text { (MOOCS) }\end{array}$ & $\begin{array}{l}\text { Cryptocurrency and blockchain may be used to } \\
\text { facilitate recording and payment for the MOOCs. }\end{array}$ \\
\hline 11 & $\begin{array}{l}\text { Smart Learning Contract: } \\
\text { financial Sponsor to } \underline{\text { Student }} \\
(\text { S2S) peers. }\end{array}$ & $\begin{array}{l}\text { Smart contracts will be triggered by academic } \\
\text { performance or built-in rules to release bitcoins, or } \\
\text { learncoins, or local fiat from sponsor to student (S2S). }\end{array}$ \\
\hline 12 & Learncoin & $\begin{array}{l}\text { Institutions, or individual students can publish their } \\
\text { funding needs, and receive learncoins from } \\
\text { spontaneous learning donors, even pseudonymously. }\end{array}$ \\
\hline 13 & Learning contract exchanges & $\begin{array}{l}\text { Suitable for continuing professional education (CPE), } \\
\text { and could benefit institutions offerings to government } \\
\text { workers, and private sector. }\end{array}$ \\
\hline 14 & Journalcoin & $\begin{array}{l}\text { The intuition of bitcoin wallets used as journalcoin } \\
\text { may be used to incentivise and earn academic brown } \\
\text { points for journal editors, reviewers, and examination } \\
\text { moderators. }\end{array}$ \\
\hline
\end{tabular}

In addition, there are real world blockchain use-cases for universities. Universities stand to benefit from industry collaboration as well as funded graduate training. University targeted blockchain exposures include, Ripple's University Blockchain Research Initiative (UBRI), University of Nicosia (Cyprus), Oxford's Blockchain University (Woolf Development), Massachusetts Institute of Technology's Blockcert project, Open University's Knowledge Media Institute, and others.

The implementation of blockchain technology is not free of challenges. New technologies are known to face implementation and adaptation difficulties. So, blockchain will not be different. Analysts (Pinna \& Ruttenberg, 2016; Mainelli, 2017; Pisa, \& Juden, 2017; Pisa \& Juden, 2017) concur that governance issues may have different degree of impact in each blockchain implementation. Possible implementation issues include: the enforcement rules for multi-distributed ledgers; dispute management among users; delegation of authority on blockchain software changes; access permission authority for network users, as well as monitoring and evaluation of system performance. In addition, the World Economic Forum (2016) sees the key barriers to large-scale implementation of blockchain technology as: the risk of non-harmonisation in global regulatory environment, and the inadequate technology 
friendly standards. Other general limitations of blockchain include privacy, initial cost outlay, and culture change issues, as well as system integrations processes.

The 4IR enthusiast, Schwab (2016) opined that: "We must develop a comprehensive and globally shared view of how technology is affecting our lives and reshaping our economic, social, cultural, and human environments. There has never been a time of greater promise, or greater peril." Nevertheless, the blockchain implementation in academia stand to also benefit from Stilgoea (2013)'s balanced “framework for responsible innovation". Meanwhile, it may be prudent to note Bartolome et al. (2017)'s caution that blockchain "... is a technology in an experimental stage."

\section{Conclusion}

The objective of this paper was to inquire whether cryptocurrency-popularised blockchain technology is an ordinary (run of the mill) computing upgrade, or whether it is an important technological advancement with potential value-add to academia and university smartness. The conclusion of the study is that the hype hypothesis allegation against blockchain is indefensible, and as such it stands to benefit both private, and public sectors, as well as institutions of academic learning. Nevertheless, the adoption of blockchain technology is likely to be hampered by disharmonious legal code, rigid governance issues, and unready corporate cultures.

\section{References}

Algan, Y. \& Cahuc, P. 2013. Trust, Institutions and Economic Development. Handbook of Economic Growth, Volume 1.

Arrow, K. 1975. Gifts and Exchanges. In E.S. Phelps (ed), Altruism, Morality and Economic Theory (pp. 13-28). New York: Russell Sage Foundation

Back, Adam. 2002. Hashcash - A Denial of Service Counter-Measure. http://www.hashcash.org/papers/hashcash.pdf

Bartolome, A.R., Bellver; C., Castaneda, L. \& Adell, J. 2017. Blockchain in Education: Introduction and Critical Review of the State of the Art. Revista Electrónica de Tecnología Educativa, 61: 1-14.

Broggi, J.D, Gallagher, M.A, Duquette, J., Nimura, C., Pattenden, M., Arbide, L.S.M., Avin, S., Kelley, K., Lidova, M., Rodríguez-Pérez, D., Slater, G. \& Winkler, A. 2018. Woolf: Building the first Blockchain University. White Paper, Woolf Development Ltd, July

Bosch, J.C. \& Hirschey, M. 1989. The valuation effects of corporate name changes. Financial Management, 18: 64-73.

Cooper, M.J., Dimitrov, O. \& Rau, P.R. 2001. A Rose. Com by any Other Name. The Journal of Finance, 56(6): 2371-2388.

Deloitte Global Blockchain Survey. 2019. Deloitte Insight Peridical, Deloitte Integrated Research. USA: Deloitte Development LLC.

Government of United Kingdom. 2016. Report for Government Office of the Chief Scientific Advisor, United Kingdom for Great Britain.

Data Breaches (n.d). List of Data Breaches from various sources. https://en.wikipedia.org/wiki/List_of_data_breaches. Access, 10 August 2018.

Diffie, W. \& Hellman, M.E. 1976. New Directions in Cryptography, IEEE Transactions on Information Theory, IT-22 (6): 644-654. 
European Central Bank 2017. How could new Technology Transform Financial Markets? April.

Haber, S. \& Stornetta, W.S. 1991. How to Time-Stamp a Digital Document. Journal of Cryptology, 3(2): 99-111.

Heinemann, C. \& Uskov, V.L. 2018. Smart University: Literature Review and Creative Analysis. In Smart Universities: Concepts, Systems, and Technologies. In Smart Innovation, Systems and Technologies, Uskov, V.L., Bakken, J.P., Howlett, R.J. \& Jain, L.C, eds., p.11-46, Switzerland: Springer.

Horsky, D. \& Swyngedouw, P. 1987. Does It Pay to Change Your Company's Name? A Stock Market Perspective. Marketing Science, 6(4): 320-335.

Hwang, G.J. 2014. Definition, Framework and Research Issues of Smart Learning Environments: a context-ware Ubiquitous Learning Perspective. Smart Learning Environment, 1(4): Springer Open.

Iansiti, M. \& Lakhani, K. 2017. Technology: The Truth about Blockchain. Harvard Business Review, January-February.

Jensen, M. \& Meckling, W. (1976): Theory of the Firm: Managerial Behavior, Agency Costs and Ownership Structure. Journal of Financial Economics 3: 305-360

Kandaswamy, R; Valdes, Furlonger; R. \& Chesini, F. 2017. Predicts 2018: Top Predictions in Blockchain Business. Garner Research Report Series, No. G00342298, November.

Karpoff, J.M. \& Rankine, G. 1994. In Search of a Signaling Effect: The Wealth Effects of Corporate Name Changes. Journal of Banking and Finance, 18: 1027-1045.

Lee, H.S. 2017. Finance in Fourth Industrial Revolution: Expected Changes and Responses. Issue Analysis Capital Market Focus, Korea Capital Market Institute, March.

Lee, P.M. 2001. What's in a name .com? The Effects of '.Com' Name Changes on Stock Prices and Trading Activity. Strategic Management Journal, 22(8):793-804.

Mainelli, M. 2017. Ask the Experts: Governance of Cryptocurrencies. The Review: The Journal of the Chartered Institute for Securities \& Investment, 7 November.

Maupin, J. 2017. Blockchains and the G20: Building an Inclusive, Transparent and Accountable Digital Economy. Centre for International Governance Innovation: G20 Policy Brief, No. 101, March.

Medcraft, G. 2017. The Fourth Industrial Revolution: Impact on Financial Services and Markets. Speech by the Chairperson of Australian Securities and Investments Commission (ASIC), Annual Forum, Hilton, Sydney. March.

Merkle, R. 1979. Secrecy, Authentication and Public key systems: A certified Digital Signature. Ph.D. Dissertation, Department of Electrical Engineering, Stanford University.

Nakamoto, S. 2008. Bitcoin: a Peer-to-Peer Electronic Cash System. Available www.bitcoin.org. Accessed February 2018.

Peng, L. \& Xiong, W. 2006. Investor Attention, Overconfidence and Category Learning. Journal of Financial Economics, 80(3): 563-602.

Pinna, A. \& Ruttenberg, W. 2016. Distributed ledger technologies in securities post-trading. European Central Bank Occasional Paper Series Paper, No.172, April.

Pisa, M. \& Juden, M. 2017. Blockchain and Economic Development: Hype vs Reality. Policy Paper 107, Centre for Global Development, Washington DC, July.

Schwab, K. 2015. The 4th Industrial Revolution: What it means and How to Respond? Foreign Affairs.

Schwab, K. 2016. The Speech Delivered on the Opening Session of the World Economic Forum Conference, Davos, 19 January.

Swan, M. 2015. Blockchain: blueprint for a new economy, Cambridge: O'Reilly Media Inc.

Stilgoea, J., Owenb, R. \& Macnaghten, P. 2013. Developing a Framework for Responsible Innovation. Research Policy, 42: 1568-1580.

Tikhomirov, V., Dneprovskaya, N. 2015. Development of Strategy for Smart University. Open Education Global International April 22-24 Conference. Banff: Canada. 
Uskov, Vladimir L., Howlett, Robert, Jain, Lakhmi C. (Eds.). 2019. Smart Education and e-Learning. Springer,

World Bank Group. 2017. Distributed Ledger Technology (DLT) and Blockchain. Fintech Note 1, Washington DC.

World Economic Forum. 2016. The Future of Financial Infrastructure An ambitious look at how Blockchain can reshape Financial Services. World Economic Forum, August. 